\title{
Didática e o Ensino da Geografia - um olhar sobre a prática docente e a
}

\section{aprendizagem}

\author{
Didactics and the Teaching of Geography - a look at teaching practice and learning \\ La Didáctica y la Enseñanza de la Geografía - una mirada a la práctica docente y al aprendizaje
}

Recebido: 02/08/2021 | Revisado: 08/08/2021 | Aceito: 11/08/2021 | Publicado: 15/08/2021

Adelcio Machado dos Santos ${ }^{1}$

ORCID: https://orcid.org.0000-0003-3916-972X Universidade Alto Vale do Rio do Peixe, Brasil E-mail: adelcio@uniarp.edu.br

Audete Alves dos Santos Caetano ${ }^{2}$ ORCID: https://orcid.org/0000-0002-9493-2639 Universidade Alto Vale do Rio do Peixe, Brasil E-mail: danieltenconi@gmail.com

Rubens Luís Freiberger ${ }^{3}$ ORCID: https://orcid.org/0000-0002-1520-1580 Universidade Alto Vale do Rio do Peixe, Brasil

E-mail: rubens.freiberger@gmail.com

Dreone Mendes ${ }^{4}$

ORCID: https://orcid.org/0000-0002-6150-0450 Universidade Alto Vale do Rio do Peixe, Brasil E-mail: dreone@gmail.com

\begin{abstract}
Resumo
O objetivo do estudo é identificar os aspectos inerentes à disciplina da Didática, tais como conceito, objeto, métodos e sua aplicação na disciplina de Geografia, para relacionar com um modelo de práticas pedagógicas que estruturem conteúdos geográficos, a partir de uma concepção dialética. A metodologia escolhida do estudo é a revisão narrativa, tipo de estudo amplo de um determinado assunto. Os resultados constatam que os métodos de ensino são propostos, classificados e descritos pela disciplina de Metodologia, porém, cabe à Didática realizar o julgamento ou a crítica destes métodos de ensino. A Didática é considerada como um método de ensino, que regula a interação entre ensino e aprendizagem, entre o educador e os educandos, resultando na assimilação consciente dos conhecimentos e no desenvolvimento das capacidades cognoscitivas e operativas do educando. Os conhecimentos da Didática são utilizados no ensino da Geografia, contribuindo para a formação dos educandos, adaptando o desenvolvimento de uma consciência crítica, voltada ao respeito dos acontecimentos mundiais, correlacionando com a configuração do espaço geográfico, reconhecendo as contradições e os conflitos econômicos, sociais e culturais, facilitando o comparativo da vida, seus hábitos, formas de utilização e/ou exploração de recursos e pessoas, em busca do respeito às diferenças e de uma organização social mais igualitária. Conclui-se que por intermédio dos procedimentos da Didática os educandos são estimulados e encaminhados, no decurso da aprendizagem, a utilizarem a Geografia para tornarem-se cidadãos capazes de se realizarem no meio social.
\end{abstract}

Palavras-chave: Didática; Educação; Metodologia de ensino; Ensino.

\begin{abstract}
The objective of the study is to identify the aspects inherent to the discipline of Didactics, such as concept, object, methods, and their application in the discipline of Geography, in order to relate them to a model of pedagogical practices that structure geographic contents, from a dialectical conception. The chosen methodology of the study is narrative review, a type of broad study of a given subject. The results show that teaching methods are proposed, classified and described by the discipline of Methodology, but it is up to Didactics to make the judgment or criticism
\end{abstract}

\footnotetext{
${ }^{1}$ Doutor em Engenharia e Gestão do Conhecimento (UFSC). Pós-Doutor em Gestão do Conhecimento (UFSC). Docente, pesquisado e orientador do Programa de Pós-graduação em Educação da Universidade Alto Vale do Rio do Peixe (UNIARP). Endereço: Rua Victor Baptista Adami, 800 - Centro Caçador/SC/Brasil. CEP 89500-199. E-mail: adelciomachado@gmail.com ORCID: https://orcid.org.0000-0003-3916-972X

${ }^{2}$ Mestranda do Programa de Pós-Graduação "Stricto Sensu” em Educação Básica da UNIARP. Instituição: Universidade Alto Vale do Rio do Peixe (UNIARP). Endereço: Rua Victor Baptista Adami, 800 - Centro - Caçador/SC/Brasil. CEP 89500-199. E-mail: danieltenconi@gmail.com ORCID: https://orcid.org/0000-0002-9493-2639

${ }^{3}$ Mestrando do Programa de Pós-Graduação em Educação Básica da UNIARP. Instituição: Universidade Alto Vale do Rio do Peixe (UNIARP). Endereço: Rua Victor Baptista Adami, 800 - Centro - Caçador/SC/Brasil. CEP 89500-199. E-mail: ruben.freiberger@ gmail.com ORCID: https://orcid.org/0000-0002-15201580

${ }^{4}$ Mestrando do Programa de Pós-Graduação "Stricto Sensu” em Educação Básica da UNIARP. Instituição: Universidade Alto Vale do Rio do Peixe (UNIARP). Endereço: Rua Victor Baptista Adami, 800 - Centro - Caçador/SC/Brasil. CEP 89500-199. E-mail: dreone@ gmail.com ORCID: https://orcid.org/0000-0002-6150-0450
} 
of these teaching methods. Didactics is considered to be a teaching method, which regulates the interaction between teaching and learning, between the educator and the students, resulting in the conscious assimilation of knowledge and the development of the student's cognitive and operational skills. The knowledge of Didactics is used in the teaching of Geography, contributing to the education of students, adapting the development of a critical consciousness, focused on the respect of world events, correlating with the configuration of geographic space, recognizing the contradictions and the economic, social and cultural conflicts, facilitating the comparison of life, their habits, forms of use and/or exploitation of resources and people, in search of respect for differences and a more egalitarian social organization. We conclude that through Didactics procedures, students are stimulated and guided, in the course of their learning, to use Geography to become citizens capable of fulfilling themselves in the social environment.

Keywords: Didactics; Education; Teaching methodology; Teaching.

\section{Resumen}

El objetivo del estudio es identificar los aspectos inherentes a la disciplina de la Didáctica, tales como, concepto, objeto, métodos y su aplicación en la disciplina de la Geografía, para relacionerse con los con un modelo de prácticas pedagógicas que estruturem los contenidos geográficos, desde una concepción dialéctica. La metodología elegida para el estudio es la revisión narrativa, tipo de estudio amplio de un tema determinado. Los resultados encontraron que los métodos de enseñanza son propuestos, clasificados y descritos por la disciplina de la Metodología, sin embargo, corresponde a la Didáctica realizar el juicio o la crítica de estos métodos de enseñanza. La didáctica se considera un método de enseñanza que regula la interacción entre la enseñanza y el aprendizaje, entre el educador y los alumnos, que tiene como resultado la asimilación consciente de los conocimientos y el desarrollo de las capacidades cognitivas y operativas del alumno. Los conocimientos de la Didáctica se utilizan en la enseñanza de la Geografía, contribuyendo a la formación de los alumnos, adecuando el desarrollo de una conciencia crítica, centrada en el respeto de los acontecimientos mundiales, correlacionando con la configuración del espacio geográfico, reconociendo las contradicciones y conflictos económicos, sociales y culturales, facilitando la comparativa de la vida, sus hábitos, formas de uso y/o explotación de los recursos y de las personas, en busca del respeto a las diferencias y de una organización social más igualitaria. Se concluye que a través de los procedimientos de la Didáctica se estimula y orienta a los alumnos, en el curso del aprendizaje, a utilizar la Geografía para convertirse en ciudadanos capaces de realizarse en el medio social.

Palabras clave: Didáctica; Educació; Metodología de la enseñanza; Enseñanza.

\section{Introdução}

A educação tem sua origem nos primórdios da civilização. Desde o início do surgimento dos grupos humanos sempre existiu a preocupação de ensinar e passar os conhecimentos para as crianças, mesmo que de forma não sistematizada.

Desse modo, a educação, como processo social, consiste na contínua transmissão dos valores do patrimônio cultural da geração adulta para a nova geração; como processo individual compreende a progressiva assimilação, por parte de cada indivíduo, dos valores, conhecimentos, ideais e técnicas, existentes no patrimônio cultural da humanidade, bem como o domínio dos processos que conduzem à criação de novos valores culturais e sociais (Santos, 2015).

O objetivo do processo educacional é assegurar a continuidade da cultura e da organização social, bem como, obter o progresso da civilização por intermédio da constante análise crítica e revisão desses valores. A educação ainda visa preparar o indivíduo para realizar-se plenamente como cidadão no meio social onde irá desenvolver seu trabalho, através de sua inserção em um contexto sociocultural em contínua transformação (Santos, 2015).

A crítica e a contínua revisão da cultura e dos valores sociais, no intento de obter progressivas superações e novos progressos em proveito da humanidade são inerentes ao processo social da educação. Para tanto, Mattos (1971) descreve que a educação é a maneira mais segura e eficaz de corrigir as deformações e os desajustes da estrutura social e às deficiências de seu funcionamento.

Assim, é relevante acrescentar que as novas gerações devem ser educadas para identificarem inadequações, buscando alternativas para solucionar os problemas que caracterizam a realidade social. Além disso, antes de educar o indivíduo para que ele se adapte as novas condições de vida, é necessário educá-lo para participar ativamente no processo histórico de transformação e melhoria da vida social. 
A Didática, como uma disciplina da Pedagogia, exerce um papel de fundamental importância dentro do contexto educacional, uma vez que estimula o entendimento e a compreensão adequada do processo de ensino, de acordo com os objetivos das disciplinas, os quais são delimitados tendo em vista o meio social dos educandos (Fernandes, Araújo, Sousa, Gomes, \& Cruz, 2018; Miranda \& Sobrinho, 2018).

É por meio das técnicas e dos procedimentos de didática que os educandos são dirigidos e orientados em sua aprendizagem. Diante do exposto, pretende-se realizar um exercício crítico-reflexivo da literatura científica sobre os aspectos inerentes à disciplina da Didática, tais como, conceito, objeto, métodos e sua aplicação na disciplina de Geografia, relacionando como um modelo de práticas pedagógicas que possibilitem a estruturação dos conteúdos geográficos, a partir de uma concepção dialética do ensino.

Deste modo, neste estudo o objetivo é identificar os aspectos inerentes à disciplina da Didática, tais como conceito, objeto, métodos e sua aplicação na disciplina de Geografia, para relacionar com um modelo de práticas pedagógicas que estruturem conteúdos geográficos, a partir de uma concepção dialética.

\section{Metodologia}

Esse estudo trata-se de uma revisão narrativa. Os pesquisadores optam pela revisão narrativa, por ser o tipo de estudo amplo de um determinado assunto, sem necessidade de definição dos critérios explícitos e sistemáticos da literatura a ser pesquisada. $\mathrm{O}$ estudo acontece sem que se precisem esgotar as fontes de informações sobre o tema de pesquisa. Também, não há necessidade de estabelecer critérios de interpretação das informações, fontes de informações utilizadas na análise da literatura científica, critérios de avaliação, seleção de trabalhos, assim interpretação das informações podem estar sujeitas à subjetividade crítica dos autores (Universidade do Estado de São Paulo, 2015; Casarin, Porto, Gabatz, Bonow, Ribeiro \& Mota, 2020).

A revisão narrativa possui a oportunidade de despertar discussões sobre determinadas temáticas, levantando inúmeras perguntas e colaborando na aquisição e atualização do conhecimento em curto espaço de tempo (Casarin, Porto, Gabatz, Bonow, Ribeiro \& Mota, 2020).

No estudo, os pesquisadores optaram pela coleta do material de forma não sistemática no período de 2010 a 2019 . Foram realizadas duas bases de dados científicas, como: Literatura Latino-Americana e do Caribe em Ciências da Saúde (LILACS) e Scientific Electronic Library Online (SciELO). O banco de informações foi sendo completados com materiais indicados pelos especialistas na temática, ao final da organização, os materiais foram lidos na íntegra, categorizados e analisados criticamente pelos pesquisadores.

\section{Resultados e Discussão}

Estudar Geografia é uma forma de entender o mundo em que habitam os seres vivos, pois é por meio desse estudo que podemos conhecer melhor os espaços, os biomas e suas especificações, estando eles localizados em uma metrópole ou na área rural, com temperaturas baixas ou altas, nas planícies, nas montanhas, na praia ou em qualquer área do planeta.

A Geografia como toda ciência é muito complexa e bastante abrangente, quando pensamos nas relações entre as sociedades e os meios que habitam, uma vez que está envolvida em inúmeros assuntos humanos e naturais. A sua abordagem está relacionada nos conceitos, associados aos conteúdos estudados na Geografia, torna-os instrumentos para a efetiva aprendizagem e permite compreender mais efetivamente a sociedade.

Segundo Sodré (1989), a geografia abrolhou com as primeiras comunidades gentílicas, sendo conferido aos gregos o pioneirismo em registrar de forma sistemática os conhecimentos geográficos. 
Dessa forma, Andrade (1987) acrescenta que os gregos, na antiguidade clássica, foram os pioneiros nos estudos sobre a medição do espaço e na discussão da forma da Terra, o estudo da física da superfície terrestre e a descrição dos aspectos físico-espaciais. Além disso, eles também trabalhavam nos sistemas agrícolas, técnicas de uso do solo, relacionamento entre as cidades e o campo, relações entre as classes sociais e entre o Poder e o povo, características naturais, os sistemas de montanha, os rios com os seus variados regimes, a distribuição das chuvas, a sucessão das estações do ano, dentre outros.

Já Santos (1986) aponta que fundamentos filosóficos da geografia foram constatados como ciência entre o final do século XIX e início do século XX, em Descartes (1596 - 1650), Kant (1724 - 1804), Darwin (1809 - 1882), Comte (1789 1857), Hegel (1770 - 1831) e Marx (1818 - 1883).

Quanto a Geografia Moderna, Capel (2004) aponta Humboldt como sendo um dos principais responsáveis por seu desenvolvimento, estando suas ideias geográficas apontadas para o da geografia física.

Pode-se compreender que no início da educação, a Geografia não era considerada uma disciplina escolar, sendo que o seu ensino estava apenas focado a estudar alguns fatos históricos e textos já prontos, servindo apenas para leituras. É neste sentido que Pessoa (2007, p. 31-32), descreve:

Durante os mais de duzentos anos de monopólio de educação jesuítica no Brasil a geografia não teve vez e nem voz nas escolas enquanto disciplina escolar. $\mathrm{O}$ ensino dos conhecimentos geográficos era secundarizado no currículo subsistente. Não existiam, também, cursos de formação de professores (as) para atuarem com o ensinamento de estes saberes. Os conhecimentos geográficos embora de grande interesse do Estado, eram até então pouco propagados nas salas de aulas.

A disciplina da Geografia no Brasil somente foi aplicada a partir do século XX, aos alunos do ensino médio e na educação superior, ingressou-se nos currículos a partir da década de 30, sendo a Universidade do Estado de São Paulo (USP) a pioneira a integrá-la nos cursos de Administração e Finanças.

Neste período, a disciplina da Geografia estava calçada apenas nas descrições e nas transmissões de conhecimento feitas pelos educadores, seguindo à risca uma metodologia tradicional baseada na reprodução dos conteúdos dos livros didáticos, sendo as aulas apenas expositivas, sem diálogo entre professor e alunos, o que de certo modo, causava grande desconforto no mundo educacional.

Com o passar dos anos, ocorreram grandes transformações na área educacional, onde a Geografia escolar passou a ser vista como uma disciplina inovadora tanto com relação às metodologias, quanto aos conteúdos ensinados, deixando de lado as questões do ensino tradicional, buscando sempre o entendimento que seu estudo se refaz no dia a dia do aluno, na medida em que o professor necessita buscar e aproximar o discente, por meio dos saberes geográficos, e contextualiza-los cotidianamente.

Essa posição foi descrita por Vieira (2007, p.13):

[...] desde o início da década de 1980, o ensino de geografia tem passado por significativas inovações em seus currículos e programas em que o especialista da área tem buscado introduzir na área do ensino as renovações teóricas metodológicas sofridas pela ciência geográfica nos últimos anos.

Diante desse novo modelo, buscou-se aplicar novas práticas educacionais que objetivam o fortalecer da educação, inserindo mecanismos e contextos que nos possibilitam almejar que determinadas transformações possam ser materializadas, sendo um dos caminhos, o desenvolvimento de pesquisas a respeito do processo de ensino-aprendizagem.

Neste sentido, Moreira (1985, p.58), assim descreve:

A geografia é um saber vivido e aprendido pela própria vivência. Um saber que nos põe em contato direto com nosso mundo exterior, com o seu todo e com cada um de seus elementos, a um só tempo. Se nisto reside sua peculiaridade, da qual deriva sua natural popularidade, reside nisto igualmente seu amplo significado político. 
Já no ano de 1996, com a criação da Lei no 9.394/96, das Diretrizes e Bases da Educação, em seu artigo 26, determina:

Art. 26. "Os currículos do ensino Fundamental e Médio devem ter uma base nacional comum, a ser complementada, em cada sistema de ensino e estabelecimento escolar, por uma parte diversificada, exigida pelas características regionais e locais da sociedade, da cultura, da economia e da clientela" (Brasil, 1996).

Com o passar dos anos, foram inúmeros modelos didáticos discutidos pelos educadores, objetivando buscar métodos de ensino que vislumbrasse os anseios de seus alunos e o mercado de trabalho na atualidade. Foi nesta linha, que em 2018, o Ministério da Educação aprovou a Base Nacional Comum Curricular (BNCC) para a Educação Infantil e o Ensino Fundamental.

A renovação no âmbito nacional ao atual modelo educacional teve sua estrutura curricular modificada, sendo a Geografia incorporada desde os anos iniciais do Ensino Fundamental. A nova abordagem proposta no documento, à ênfase recai sobre o pensamento espacial e o raciocínio geográfico. A Geografia na BNCC tem como pressuposição a ideia de que, para abarcar o mundo em que se vive, é preciso aprender sobre as distintas sociedades existentes nas diversas regiões do planeta e formar um conceito de identidade.

No processo educacional, como bem sabemos, mesclar conceitos e correntes de pensamento geográfico é fundamental, pois vivemos em um mundo globalizado, onde as informações cada vez mais têm papel fundamental. Neste sentido, a disciplina de Geografia e o seu ensino devem ser desenvolvidos de forma dinâmica aproximando os alunos dos aspectos mais relevantes e dos acontecimentos atualizados que envolvam toda a nação e o mundo.

É neste contexto, que Nérici (1997) sustenta que a metodologia da Didática apresenta estruturações preponderantemente lógicas ou psicológicas, seguindo as circunstâncias e o nível de maturidade do educando, pois os elementos básicos, de um método de ensino são: a linguagem didática, tanto oral como escrita; os meios auxiliares e o material didático; e a ação didática propriamente dita.

Libâneo (1990) discorre que o processo de ensino se define com uma proposta de uma sequência de atividades que envolvem o educador e os educandos, com a proposta de assimilação de conhecimentos e desenvolvimento de habilidades, por meio dos quais os educandos refinam as capacidades cognitivas, tais como: pensamento independente, observação, análisesíntese e outras.

É nesta premissa que o uso da didática é considerado como um método de ensino, que regula a interação entre ensino e aprendizagem, entre o educador e os educandos, resultando na assimilação consciente dos conhecimentos e no desenvolvimento das capacidades cognoscitivas e operativas do educando.

De acordo com Libâneo (1990), a escolha e a organização dos métodos de ensino devem suprir à necessária unidade entre objetivos-conteúdos-métodos e formas de organização do ensino, juntamente com as condições concretas das situações didáticas.

Passando para essa nova modalidade do ensino brasileiro, e com a sociedade voltada para o processo econômico, do conhecimento, tecnológico e da comunicação, é que podemos realizar diagnósticos sobre o modo de vida dos cidadãos, suas relações e influências globalizadas que constituem oportunidades culturais estimulantes e interessantes a todos os indivíduos e organizações, utilizando-se assim de métodos eficazes que colaborarão no processo educacional.

Deste modo, como desafios e exigências extraordinários, faz sentido em haver uma educação que esteja voltada para a aplicação de métodos de ensino que não se resumam a um conjunto de procedimentos, mas envolvam ações, passos e procedimentos relacionados ao método de reflexão, compreensão e transformação da realidade, que, em cada situação didática, assegure o encontro formativo entre o aluno e as matérias de ensino. 
No mesmo sentido, Belloni (1998) acrescenta que é preciso separar e entender o que é proveitoso no processo educacional. Isto porque, como bem descreve o autor, o uso de materiais sem procedências não facilita o aprendizado, como também, os programas televisionais sem conteúdos didáticos, não promovam conhecimento.

É nesta linha que passamos a entender que a escola pode ser um espaço de inovação, de imersão, de experimentação saudável de novos caminhos. Não precisamos romper com tudo, mas programar mudanças e supervisioná-las com equilíbrio e maturidade. São muitos os recursos a nossa disposição para aprender e para ensinar.

Podemos destacar como um novo recurso educacional o uso da Internet, dos programas que gerenciam grupos e possibilitam a publicação de materiais didáticos, com bom uso no âmbito educacional. Estando mais do que na hora, de evoluir, modificar nossas propostas, aprender fazendo.

É nesta linha que Teruya (2006), Brito e Purificação (2008) revelam a necessidade da formação do professor incentivar a análise crítica e reflexiva sobre o uso de tecnologias em sua prática pedagógica, tendo em vista os avanços científicos e tecnológicos presentes no mundo atual, que vem promovendo novas formas de se conceber o processo educativo.

É imperioso acrescentar que os métodos de ensino são propostos, classificados e descritos pela disciplina de Metodologia, porém, cabe à Didática realizar o julgamento ou a crítica destes métodos de ensino. Neste sentido, um método consiste em uma forma disciplinada, ordeira e calculada de prosseguir para se alcançar um objetivo visado.

Para Vieira e Santos (2019), o uso da tecnologia no âmbito educacional há de se considerar de extrema relevância. Isto porque, segundo os autores, a tecnologia é muito mais que apenas equipamentos, máquinas e computadores. Ela é vista como uma operação de dois sistemas que dependem um do outro de maneira variada, consagrando resultados satisfatórios como meio de inclusão e comunicação. A tecnologia deve ser vista como meio facilitador, que permita aos alunos aulas mais atraentes, facilitando o acesso a conteúdos e levando mais dinamicidade para o aprendizado, e na disciplina de Geografia há que se considerar que todo esse processo ajudará na busca de informações e conteúdos atualizados que fortaleceram o seu aprendizado.

Nos dias de hoje, encontram-se disponíveis para os educadores e alunos diversos sites oficiais que produzem conteúdos relevantes, com muitos materiais que podem ser utilizados como ferramentas de aprendizagem. Como exemplo citase "Escola Educação", um portal direcionado a professores e alunos, o qual disponibiliza conteúdos para pesquisas escolares, atividades educativas, cursos gratuitos e artigos para professores, podendo ser acessado em https://escolaeducacao.com.br/. Outro site relevante é o "Planeta Educação", que disponibiliza um mundo de informação sobre questões educativa, podendo ser acessado em https://www.plannetaeducacao.com.br/ e outros inúmeros programas educativos que ajudam na elaboração de conteúdos voltados ao aprendizado.

Já no âmbito da disciplina de Geografia, existem muitos materiais disponíveis para os alunos e professores que podem ser utilizados como ferramentas didáticas, para contribuir nas pesquisas e conteúdos em sala de aula. Podemos citar como exemplos os chamados Recursos Educacionais Abertos (REA), que incluem: textos, livros, planos de aula, jogos, imagens, vídeos ou áudios, softwares e jogos, imagens. Uma das plataformas mais acessadas está a "Recursos Adicionais com licença Aberta" (REliA), alocada na página https://relia.org.br/geoda/, a "Escola Digital" pode ser acessada em https://escoladigital.org.br/odas/os-terremotos-49173, dentre outros.

Partindo dessa premissa, verifica-se que cabe ao educador buscar meios educacionais que facilitem a administração de seus conteúdos, e a tecnologia poder ser um meio eficaz do encaminhamento das tarefas, a dinâmica do processo de aprendizagem, a aproximação com seus alunos, à troca de experiências, garantindo uma sala de aula proativa, com mudanças positivas na prática pedagógica.

Assim, a discussão sobre o papel da didática no processo de ensino-aprendizagem leva-nos a refletir sobre uma educação que deve ser oportunizada e acessada por todos, garantido o respeito às particularidades individuais dos envolvidos 
no processo de educacional e que respeite as suas peculiaridades. Partindo dessa análise, torna-se indispensável uma mudança na transmissão de conhecimentos no âmbito escolar, realizando uma reformulação do ato educativo, que busque despertar a criticidade dos cidadãos em face à realidade.

Todo processo pedagógico passa pela premissa do planejamento e desenvolvimento de suas aulas, quando utilizada de maneira eficiente, os resultados alcançam suas expectativas educacionais. Nesta linha, Strore \& Montavoni (2018 apud Moran 2013, p. 9-10), assim descrevem:

Escolas não conectadas são escolas incompletas (mesmo quando didaticamente avançadas). Alunos sem acesso contínuo às redes digitais estão excluídos de uma parte importante da aprendizagem atual: do acesso à informação variada e disponível on-line, da pesquisa rápida em bases de dados, bibliotecas digitais, portais educacionais, da participação em comunidades de interesse, nos debates e publicações on-line, enfim, da variada oferta de serviços digitais.

É relevante acrescentar que a criação e a ampliação das tecnologias de informação e comunicação no mundo do trabalho transformam as condições da existência humana, melhorando a vida dos indivíduos. Quando tratamos dos temas voltados a disciplina da Geografia, é fundamental a sua contextualização no entorno do ensino, pois ela proporciona a compreensão das relações que ocorrem em todas as escalas. O espaço vivido é algo a se considerar sempre, principalmente na abordagem de um tema que envolve, direta e indiretamente, todas as pessoas e países.

É pensando nesta prática que Bacich e Moran (2018), descreve que a participação de crianças e jovens na vida adulta, seja no trabalho, no bairro em que morem, no lazer, nos espaços de prática política explícita, certamente será de melhor qualidade se estes conseguirem pensar sobre seu espaço de forma mais abrangente e crítica.

Por essa linha de pensamento, fica evidente a necessidade de se repensar as práticas pedagógicas nas disciplinas, considerando que o estudo deste conteúdo deve sempre estar voltado à realidade dos nossos alunos, em especial, no lugar de sua vivência. Neste seguimento que os Parâmetros Curriculares Nacionais para o Ensino Médio (PCNEM) ressaltam também sobre a ciência geográfica:

Diante da revolução na informação e na comunicação, nas relações de trabalho e nas novas tecnologias que se estabeleceram nas últimas décadas, podemos afirmar: o aluno do século XXI terá na ciência geográfica importante fonte para sua formação como cidadão que trabalha com novas ideias e interpretações em escalas onde o local e o global definem-se numa verdadeira rede que comunica pessoas, funções, palavras, ideias (Brasil, 1999, p. 31).

Assim, a ciência geográfica deve ir além de um componente curricular e contribuir para o desenvolvimento do aluno como sujeito ativo da história, como bem defende Candau (2011), quando afirma que a didática é responsável por mostrar o caminho por meio dos métodos e das técnicas, que levem a aprendizagem e a natureza do conhecimento.

Há de se destacar que existem inúmeras formas didáticas de planejar e aplicar conteúdos educacionais, estando sempre à geografia na modalidade de entender a dinâmica do espaço para auxiliar no planejamento das ações do homem sobre ele. Trabalhar com os diferentes biomas, as formas de relevo, os fenômenos climáticos, as composições sociais, os hábitos humanos nos diferentes lugares são imprescindíveis para a manutenção da vida em sociedade.

Esse entendimento é seguido por Silva, Santos, Dias e Vidal (2020), quando discorrem que o enfoque disciplinar atual é o resultado da postura científica altamente racional e rígida que requer a excessiva particularização e fragmentação, resultando em alienação e esgotamento do ser humano. Com plena convicção que teoria e prática são inseparáveis, possibilitando avanço no desenvolvimento pessoal e intelectual.

Nesse sentido, cada elemento da prática educativa deve ser visto em um processo conjunto e não como fatores isolados de uma realidade única. Isso requer que o professor tenha um maior conhecimento pedagógico e didático, para que consiga articular diferentes estruturas na busca da construção de um todo em qualquer disciplina (Ladeira \& Leão, 2021). 
A disciplina de Geografia contribui para a formação de seus educandos, adaptando o desenvolvimento de uma consciência crítica, voltada ao respeito dos acontecimentos mundiais, correlacionando com a configuração do espaço geográfico, reconhecendo as contradições e os conflitos econômicos, sociais e culturais, facilitando o comparativo da vida, seus hábitos, formas de utilização e/ou exploração de recursos e pessoas, em busca do respeito às diferenças e de uma organização social mais igualitária.

Portanto, a partir desta perspectiva, poder tornar o educando ator do processo ensino-aprendizagem. Incentiva-o a entender as variadas escalas na Geografia: local, regional, nacional e global. A autonomia que a identidade do cidadão confere é necessária para expressar sua responsabilidade com o seu "lugar-mundo", através de sua identidade territorial (Siqueira, Soares \& Oliveira, 2020).

Assim, a Didática é uma disciplina teórico-prática que auxilia o professor em todos os rudimentos constitutivos da dinâmica escolar, abrangendo a reflexão pedagógica indispensável à implementação de um projeto educativo, com suas concepções apontadas através de seus planejamentos e efetivadas através de sua dinâmica cotidiana (Melo \& Urbanetz, 2008).

Nesta linha, é relevante fazer uma reflexão sobre os modelos didáticos implantados no âmbito educacional, estando eles ligados aos fatores fundamentais no processo de aprendizagem. Desta forma, o uso de novas tecnologias pode obscurecer a contribuição dos trabalhos pedagógicos e didáticos contemporâneos, pois eles facilitam a criação de processos de aprendizagem, ricos em detalhes, por meio de uma divisão de trabalho, uma vez que, tanto a informação, quanto a dimensão interativa são assumidas pelos produtores dos instrumentos.

Segundo Salvador, Barreto e Cruz (2021) um educando que não teve uma base educativa completa e satisfatória, não pode ser comparado com outro educando que teve uma boa preparação escolar. É inevitável que todo esse fracasso sempre seja associado à escola e ao seu educador. É nesse cotidiano esperançoso que podemos levar para a sala de aula, formas de aprendizados que corroboram e levam os alunos a perceberem que estão inseridos no espaço geográfico como agentes transformadores.

Do mesmo modo, Candau (2005) pondera que a prática deve ser um aproveitamento da teoria, se considerarmos que as diferenças básicas entre os indivíduos e outros seres vivos conhecidos se atrelam às possibilidades de suas consciências, restando claro, que toda atividade será mais ou menos humana, na medida em que conecta ou desvincula a ação à reflexão.

Na mesma linha, Freire (1979) discorre que atualmente há a concepção que a educação é um elemento de transformação social, e para que isso ocorra, é necessário fazer uma reflexão pedagógica, na qual se procure questionar essa visão tradicional.

O desafio primordial do educador em Geografia será fazer ligações com os conhecimentos que o educando tem aprendido no dia a dia com o conhecimento científico desenvolvido em sala de aula. Para que ocorra o ensino e aprendizagem de Geografia, esse aspecto se faz cada vez mais basilar (Ladeira \& Leão, 2021).

A utilização da didática para ostentar um papel significativo na prática educacional do educador e da formação dos educados, não poderá reduzir-se e dedicar-se somente ao ensino de meios e mecanismos, pelos quais desenvolvem um processo de ensino-aprendizagem. É preciso criar um modelo crítico com práticas educativas alinhadas a um projeto histórico revisado cotidianamente, que não será construído tão somente pelo educador, mas, por ele conjuntamente com os educandos e outros membros dos diversos setores da sociedade.

Os métodos avaliativos constituem a importância do professor no papel de educador, qualificando seus métodos, de forma que os educandos tenham seus princípios individuais respeitados, já nem sempre a realidade é igual para todos no que diz respeito ao contexto social (Oliveira, 1988).

Nesse sentido, a didática é responsável por mostrar o caminho por meio dos métodos e das técnicas que levem a aprendizagem e a natureza do conhecimento (Ladeira \& Leão, 2021). Neste sentido, a didática deve agir como mecanismo de 
tradução prática, no exercício educativo, de decisões filosófico-políticas e epistemológicas de um projeto histórico de desenvolvimento do povo. Ao exercer seu papel específico, apresenta-se como o mecanismo tradutor de posturas teóricas e práticas educativas.

\section{Considerações Finais}

A educação escolar é o processo no qual são democratizadas as informações, os valores e a cultura da sociedade, possibilitando que os indivíduos adquiram conhecimentos e a capacidade de pensar criticamente os problemas e desafios postos pela realidade social vigente. Esse processo educativo só é possível por meio da utilização de modelos didáticos, que exercem papel fundamental no alcance eficiente dos objetivos educacionais.

A didática pode ser definida como sendo o estudo acerca das técnicas relacionadas ao processo de ensinoaprendizagem, ou seja, é uma disciplina que estuda a técnica do ensino em todos os seus aspectos práticos e operacionais. Ela engloba um conjunto sistemático de princípios, normas, recursos e procedimentos específicos, cuja função consiste em orientar os alunos na aprendizagem das matérias programadas, tendo em vista seus objetivos educativos.

O planejamento escolar e a avaliação são elementos constitutivos da disciplina de Didática. Enquanto o planejamento possibilita a definição dos resultados que se pretende alcançar, com que recursos materiais e humanos, e mediante que procedimentos, estratégias e técnicas, a constante avaliação do processo educador e educando permitem identificar se a educação está atingindo os resultados propostos.

Os métodos de ensino também são objeto de estudo da Didática, a qual é responsável por realizar o julgamento ou a crítica dos mesmos. O processo consiste na organização racional e prática dos recursos e procedimentos do educador, no intento de conduzir a aprendizagem dos educandos aos resultados previstos pelo sistema educacional, o que leva a crer que toda essa gama, ao ser aplicado no âmbito da Geografia, traz resultados satisfatórios e compensadores para a Educação.

É neste sentido que entendemos que a Didática se torna um método eficaz e modelador, contribuindo de forma substancial nos métodos de ensino em todos os níveis educacionais, e na disciplina da Geografia poderá fortalecer os processos educacionais implantados, amadurecendo o aprendizado dos educandos, tornando-se assim, mais dinâmico e eficaz.

Ressalta-se que o objetivo desse estudo foi o de verificar qual é a função verdadeira da Didática e como ela pode contribuir para a melhoria deste contexto no âmbito da disciplina de Geografia, o que, de sorte, verificou-se que a sua prática desempenha papel significativo na elaboração de técnicas pelas quais se deseje desenvolver um processo de ensino aprendizagem.

Sugerimos que sejam realizados estudos futuros com professores que utilizem a Didática no ensino da Geografia, a aproximação o ensino com a prática da sala de aula, pode contribuir para que outros docentes, até de outras áreas, se sintam estimulados a usa-la em suas atividades.

Por fim, por intermédio dos procedimentos da Didática os educandos são estimulados, e encaminhados, de forma eficaz, no decurso da aprendizagem, a utilizarem a Geografia para tornarem-se cidadãos capazes de se realizarem no meio social em qualquer lugar do mundo.

\section{Referências}

Andrade, M. C. (1987). Geografia, ciência da sociedade: uma introdução à análise do pensamento geográfico. Atlas.

Bacich, L. \& Moran, J. (1998). Metodologias ativas para uma educação inovadora: uma abordagem téorico-prática. Penso.

Belloni, M. L. (1988). Tecnologia e formação de professores: rumo a uma pedagogia pós-moderna? Educ. Soc., 19 (65), 143-162. https://www.scielo.br/j /es/a/D k5N9LWLmSFgkYf6Tq4BKks/abstract/?lang=pt

Brasil. (1996). Lei $n^{\circ}$ 9394, de 20 de dezembro de 1996. Estabelece as diretrizes e bases da educação nacional. Ministério da Educação. http://port al.me c.gov.br/seesp/arquivos/pdf/lei9394_ldbn1.pdf 
Brasil. (1999). Parâmetros curriculares nacionais: ciências humanas e suas tecnologias. Ministério da Educação. http://portal.mec.gov.br/seb/arquiv os/pdf/cien ciah.pdf

Brito, G. S. \& Purificação, I. (2008). Educação e novas tecnologias. (2a ed.). InterSaberes.

Candau, V. M. (2005). Rumo a uma Nova Didática. (16a ed.). Vozes.

Candau, V. M. (2011). Rumo a uma Nova Didática. (21a ed.). Vozes.

Capel, H. (2004). Filosofia e ciência na geografia contemporânea: uma introdução à geografia. (2a ed.). Massoni.

Casarin, S. T., Porto, A. R., Gabatz, R. I. B., Bonow, C. A., Ribeiro, J. P., \& Mota, M. S. (2020). Tipos de revisão de literatura: considerações das editoras do Journal of Nursing and Health. J. nurs. Health, 10 (esp.), e20104031. https://periodicos.ufpel.edu.br/ojs2/index.php/enfermagem/article/view/19924

Fernandes, T. G., Araújo, B. G. O., Sousa, D. M., Gomes, T. Q. \& Cruz, M. L. B. (2018). A construção de maquetes como recurso didático no ensino de Geografia. Revista Equador (UFPI), 7 (2), 96-109. https://comunicata.ufpi.br/index.php/equador/article/view/7742/4904

Freire, P. (1979). Educação e mudança. (23a ed.). Paz e Terra.

Ladeira, F. F. \& Leão, V. P. A. (2021). Geopolítica mundial na mídia e seus reflexos no processo de ensino-aprendizagem em geografia na educação básica. Revista Educação Geográfica em Foco, 5 (9), 1-15. http://periodicos.puc-rio.br/index.php/revistaeducacaogeograficaemfoco/article/view/1097

Libâneo, J. C. (1990). Didática. Cortez.

Mattos, L. A. (1971). Sumário de didática geral. (10a ed.). Aurora.

Melo, A. \& Urbanetz, S. T. (2008). Fundamentos da Didática. Ibpex.

Miranda, C. R. \& Sobrinho, A. D. C. (2018). A importância da didática no ensino superior. Revista da Pós-Graduação Multidisciplinar - RPGM, 1 (4),197206. https://www.fics.edu.br/index.php/rpgm/article/view/783

Moreira, R. (1985). O que é geografia. (5a ed.). Brasiliense.

Nérici, I. G. (1987). Metodologia do ensino: uma introdução. Atlas.

Oliveira, M. R. N. S. (1988). Histórico da Didática. In M. R. N. S. Oliveira (Org.), O Conteúdo da Didática: um discurso da neutralidade científica. pp. 33-47. UFMG.

Pessoa, R. B. (2007). Um olhar sobre a trajetória da geografia escolar no Brasil e a visão dos alunos de ensino médio sobre a geografia atual. (Dissertação de mestrado). Universidade Federal da Paraíba.https://www.ufpb.br/ppgg/contents/documentos/dissertacoes/rodrigo_pessoa.pdf

Salvador, N. K. C., Barreto, G. L. S. \& Cruz, I. S. F. Cidadania (ins)desejada: fortalecendo a democracia. Revista Caravana - Diálogos entre Extensão e Sociedade, 6 (1), 62-76. http://caravana.ifpe.edu.br/index.php/caravana/article/view/481/pdf_1

Santos, M. (1986). Por uma Geografia nova: da crítica de geografia a uma geografia crítica. Hucitec.

Santos, A. M. (2015). Saudações aos professores por Adélcio Machado. http://rcnonline.com.br/artigos/artigo-sauda\%C3\%A7\%C3\%B5es-aos-professorespor-adelcio-machado-1.1821862

Silva, K. R., Santos, L. G. S., Dias, M. H. P., Vidal, V. C \& Alves, R. C. Aprender fazendo: breve relato de experiência a partir do estágio supervisionado em Geografia (UNIMONTES). Revista Ciranda, 4 (1), 54-66. https://www.periodicos.unimontes.br/index.php/ciranda/article/view/1571

Siqueira, A. L. F., Soares, M. M. C. \& Oliveira, A. M. A educação do campo e a cidadania juvenil: uma aproximação om o projeto nós propomos! Revista Homem, Espaço e Tempo, Sobral, 14 (3), 179-197. https://rhet.uvanet.br/index.php/rhet/article/view/490/321

Sodré, N. W. (1989). Introdução à geografia: geografia e ideologia. (7a ed.). Vozes.

Stroher, A. P. \& Mantovani, D. (2018). Tecnologias em salas de aula: o uso das redes sociais como ferramenta no processo de ensino e aprendizagem. Revista Científica SMG, 6 (2), 1-19. https://revista.smg.edu.br/index.php/cientifica/article/view/11/15

Teruya, T. K. (2006). Trabalho e educação na era midiática: um estudo sobre o mundo trabalho na era da mídia e seus reflexos na educação. Eduem.

Universidade do Estado de São Paulo. (2015). Tipos de revisão de literatura. Biblioteca Prof. Paulo Carvalho Mattos, Faculdade de Ciências Agronômicas UNESP Campus Botucatu. https://www.fca.unesp.br/Home/Biblioteca/tipos-de-evisao-de-literatura.pdf

Vieira, N. R. (2007). As questões das geografias do ensino superior e do ensino fundamental a partir da formação continuada do professor e das categorias lugar, paisagem, território e região: um estudo da diretoria regional de ensino de Marilia- SP. 2007. (Tese de doutorado). Universidade Estadual Paulista Júlio de Mesquita Filho.https://repositorio.unesp.br/handle/11449/101429

Vieira, J. M. \& Santos, R. (2019). As novas tecnologias para a educandos cegos: um ensino geográfico. Revista de Humanidades, Tecnologia e Cultura RehuTec, 8 (1), 1-19. http://fatecbauru.edu.br/ojs/index.php/rehutec/article/view/177/280 